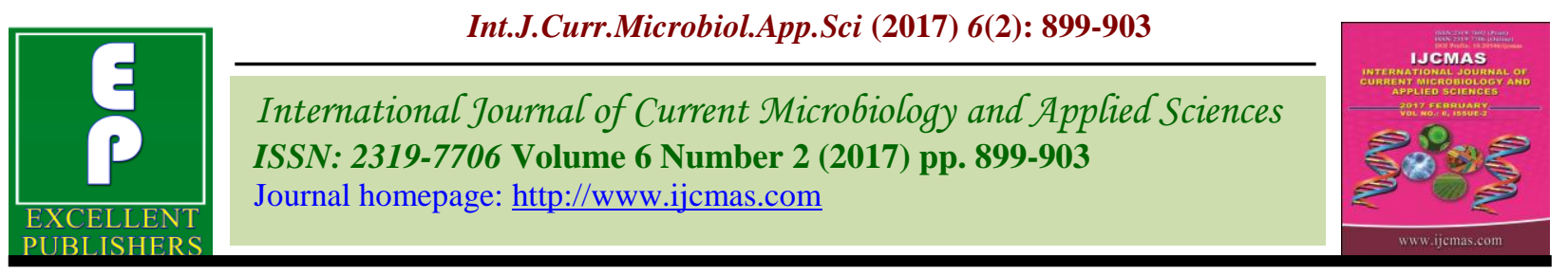

Original Research Article

http://dx.doi.org/10.20546/ijcmas.2017.602.100

\title{
Coprological Survey of Gastrointestinal Parasites of Dairy Cattle in Wayanad, Kerala, India
}

\section{Mathew Abraham, Pallippatt Thoomban Harshal, Karapparambu Gopalan Ajithkumar and Reghu Ravindran*}

Department of Veterinary Parasitology, College of Veterinary and Animal Sciences, Pookode, Wayanad, Kerala-673576, India

*Corresponding author:

\section{A B S T R A C T}

\section{Keywords}

Cattle,

Gastrointestinal parasites, Wayanad, Kerala, India.

\section{Article Info}

Accepted:

20 January 2017

Available Online:

10 February 2017
A study was conducted during the period, August 2009 to July 2010 for identification of the ova of gastrointestinal parasites of cattle of Wayanad district, Kerala. Bovine faecal samples $(n=860)$ were collected from all the 25 panchayaths of district. Ova of strongyle (17.56\%) and amphistomes $(11.86 \%)$ were the most prevalent followed by strongyloides $(1.86 \%)$, moniezia $(0.3 \%)$ trichurid $(0.2 \%)$ and schistosoma $(0.1 \%)$. Mixed infection was evident in $1.62 \%$ cattle.

\section{Introduction}

Diseases and feed scarcity are observed as the major constraints of dairy production (Birthal and Jha, 2005). The total estimated economic losses due to all livestock diseases in Kerala amounts to 832.82 crores in the year 2007 (ADSS, 2007). Parasitism contributes to 31 per cent of livestock diseases and were reported more in cattle (13.83 per cent) followed by poultry ( 9.71 per cent) and goat (5.62 per cent) (ADSS, 2007). Out of the total economic loss of 294.44 Crores due to parasitism, 202.82 crores were attributed to the parasitic diseases of cattle alone (ADSS, 2007).
Wayanad district is located $11.27^{\prime}$ to $15.38^{\prime}$ north latitude and $75.47^{\prime}$ to $70.27^{\prime}$ ' east longitude. The district is divided into three taluks and each taluk has a number of panchayaths. The taluks are Vythiri (consisting of panchayaths viz., Vythiri, Pozhuthana, Thariyoade, Padinjarethara, Meppadi, Vaduvanchal, Kaniyampetta, Kottathara and Vengapally), Sulthan Bathery (consisting of panchayaths viz., Sulthan bathery, Nenmeni, Meenangady, Ambalavayal, Muttil, Pulpally, Mullomkolli, Noolpuzha and Poothady) and Manathavady (consisting of panchayaths viz., Thondarnad, Edavaka, Thalappuzha, Mananthavady, Vellamunda, Thirunelli and Panamaram). 
Cattle population in Wayanad was 88,135 according to Quinquennial livestock census, 2007. Each panchayath in this district has a veterinary institution with one veterinarian and 1-2 livestock inspectors. Dewormers are provided to farmers (usually free of cost) as and when they approach these institutions. Majority of cattle in this district are crossbreds (crossbreds of Jersey, Holstein Fresian or Swiss Brown with the indigenous cattle) with high lactation yield.

Gastrointestinal helminths can affect feed intake, feed utilization and growth rate (Coop and Holmes, 1996; Coop and Kyriazakis, 1999) which will ultimately result in reduced milk production and reproductive performance. Severe clinical parasitism can result in sick, moribund animals, some of which may die, despite anthelmintic treatment. The cost of failure to control of parasites should be measured not just in terms of productivity but also in the well-being of animals; parasitism representing a significant threat to animal welfare (Sutherland and Scott, 2010).

The prevalence and effects of gastrointestinal (GI) helminths vary considerably depending on the genera involved, the animal species, and local environmental conditions such as humidity, temperature, rainfall, vegetation, and management practices.

There is a need for a periodic surveillance of parasitism within a given environment for successful formulation and implementation of an efficient and effective worm control strategy. There is no documented information on the prevalence of GI helminth infections of cattle in the Wayanad district of Kerala, India. Hence, the present study aims to undertake extensive survey based on identification of the ova of endoparasites causing parasitic gastroenteritis in cattle.

\section{Materials and Methods}

The study was conducted during the period August 2009 to July 2010. Faecal samples were collected from dairy cattle (of age 6 months and above), from all the 25 panchayaths of Wayanad district. Sample bottles were distributed to the farmers supplying milk to various milk societies of the district on a day before collection. Samples were collected from animals kept by individual households and not from farms. Samples were collected from those animals, which were not dewormed at least one month prior to sampling. Faecal samples $(\sim 25 \mathrm{~g})$ were collected by farmers from the top portion of the freshly passed out faeces and were labeled properly. Data on the age of the animals were collected. They were immediately transported on the day of collection to the Department of Veterinary Parasitology, College of Veterinary and Animal Sciences, Pookode and were preserved in 10 per cent formalin until processed. They were processed through sedimentation by centrifugation. A small quantity of faeces $(5 \mathrm{~g})$ was emulsified with $10-15 \mathrm{~mL}$ of water in a mortar and the emulsion was strained through a sieve to remove coarser particles and debris. The filtrate was collected in a centrifuge tube and was centrifuged for 2-3 minutes at 1000-2000 rpm. The supernatant fluid was removed and the sediment was examined under the microscope (10X objective) for the presence of eggs. Parasitic ova were identified based on the descriptions provided by Soulsby (1982).

\section{Results and Discussion}

A total of 860 bovine faecal samples from twenty five panchayaths were examined for the presence of parasitic ova. Taluk wise prevalence of gastrointestinal parasitism of cattle of Wayanad district is represented in 
table1. Maximum prevalence of parasitism was observed in Vythiri thaluk (40.96\%), followed by Manathavady (33.18\%) and Sulthanbathery $(21.19 \%)$ based on single infections. Prevalence of infection based on age of the sampled animals is depicted in table 2. Prevalence of strongyle infections was similar in all age groups. Amphistome infections were more common in animals aged more than two years.

A map on endemicity of different parasitic diseases causing gastroenteritis in cattle of Wayanad district (Fig.1) revealed increased prevalence of amphistomosis in south-western parts of the district (Padinjarethara,
Thondarnad, Pozhuthana and Vythiri) Increased prevalence of amphistomosis was also seen in north and north-eastern parts (Thirunelli, Mullankolli and Sulthanbatheri).

In the present study, it was observed that that strongylosis was the most predominant helminthic disease irrespective of the age group and area, followed by amphistomosis. Strongyle infection was predominant in central parts of the district. Parasitic gastroenteritis (PGE) causes huge economic lose in the form of death or reduction in milk production due to inappetance (Radostits et al., 2000).

Table.1 Taluk wise data on prevalence of gastrointestinal parasitism in cattle of Wayanad District

\begin{tabular}{|c|c|c|c|c|c|c|c|c|}
\hline Taluk & $\begin{array}{c}\text { Number } \\
\text { examined }\end{array}$ & S & Sd & T & A & Sh & M & Md \\
\hline Vythiri & 332 & 69 & 9 & 1 & 55 & 1 & 1 & 7 \\
\hline Mananthavady & 226 & 44 & 4 & 1 & 25 & 0 & 1 & 4 \\
\hline Sulthan Batheri & 302 & 38 & 3 & 0 & 22 & 0 & 1 & 3 \\
\hline Total & 860 & 151 & 16 & 2 & 102 & 1 & 3 & 14 \\
\hline \% Prevalence & & 17.56 & 1.86 & 0.2 & 11.86 & 0.1 & 0.3 & 1.62 \\
\hline
\end{tabular}

S - Strongyle ova, Sd- Strongyloides ova, T- Trichuris ova, A- Amphistome ova

Sh- Schistosoma spindale ova, M-Moniezia ova, Md-Mixed infection

Table.2 Prevalence of gastrointestinal parasitic infections in different age groups of cattle of Wayanad

\begin{tabular}{|c|c|c|c|c|c|c|c|c|}
\hline Age & Number & \multicolumn{7}{|c|}{$(\%$ prevalence $)$} \\
\cline { 3 - 9 } & examined & $\mathrm{S}$ & $\mathrm{Sd}$ & $\mathrm{T}$ & $\mathrm{A}$ & $\mathrm{Sh}$ & $\mathrm{M}$ & $\mathrm{Md}$ \\
\hline 6 m-2 years & 140 & 19.3 & 0 & 0.7 & 5 & 0 & 0.7 & 2.1 \\
\hline 2-6 years & 510 & 17.6 & 2.55 & 0.2 & 13.5 & 0.2 & 0.2 & 2.2 \\
\hline >6years & 210 & 16.2 & 1.4 & 0 & 11.9 & 0 & 0.47 & 0 \\
\hline
\end{tabular}

S - Strongyle ova, Sd- Strongyloides ova, T- Trichuris ova, A- Amphistome ova, Sh-Schistosoma spindale ova, M-Moniezia ova, Md-Mixed infection 
Fig.1 A map on endemicity of different parasitic diseases causing gastroenteritis in cattle of Wayanad district

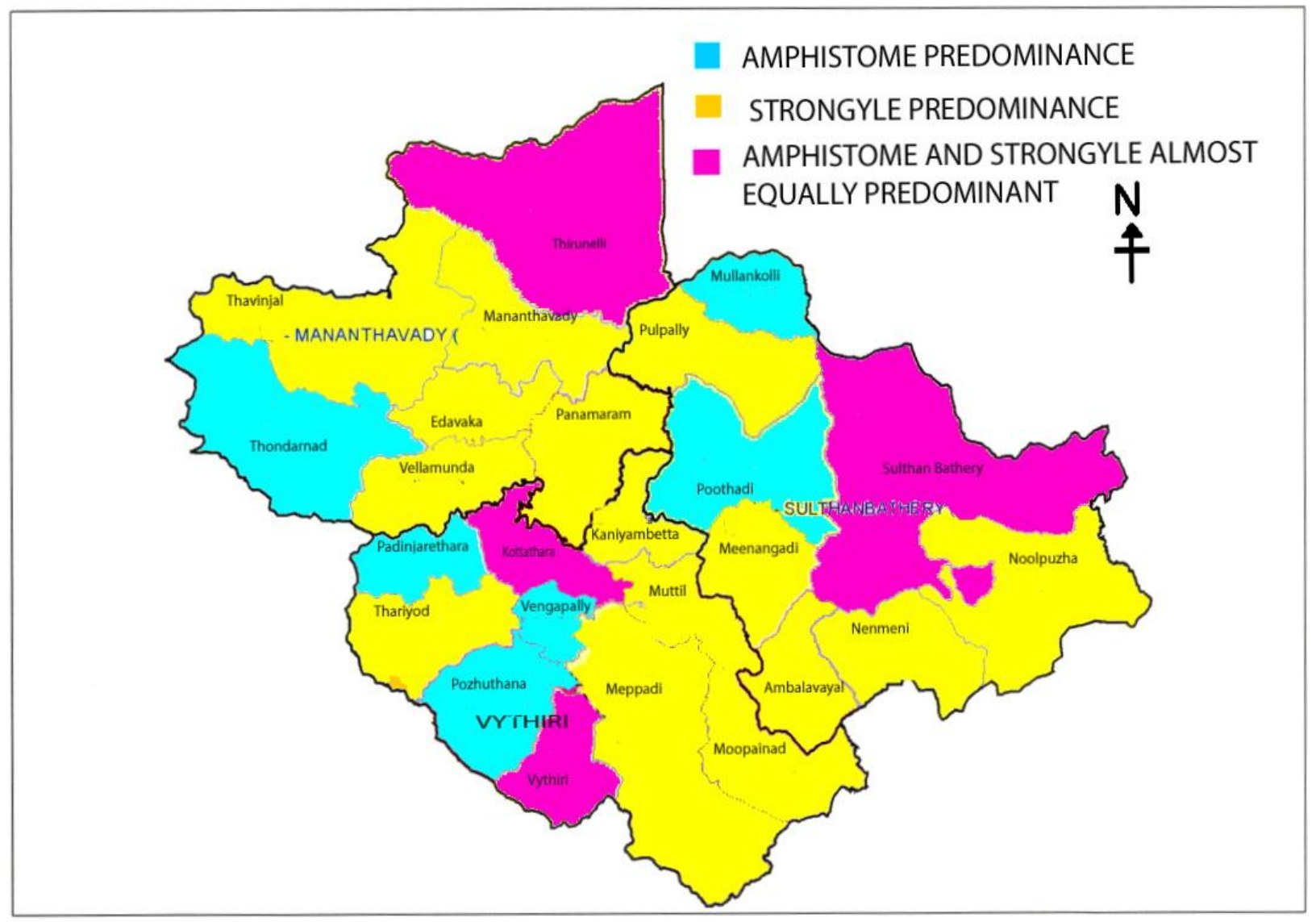

The map showing the endemicity of parasites indicated increased prevalence of amphistomosis in south-western, north and north-eastern parts of the district. Southwestern Wayanad is rich with water bodies including dams while the north ad northeastern parts have very good forest cover. These water bodies harbour the snails which are the vectors of paramphistomes. However, flukes of the family Paramphistomidae commonly encountered in the rumen of cattle produce no symptoms or lesions while weakness, anaemia and diarrhoea were reported due to infection with immature flukes (Radostits et al., 2000). Effective control of these diseases is possible with integrated programmes including proper diagnosis, sound managemental practices and strategic use of anthelmintics.
Proper diagnosis of parasitism can help in identification of managemental or chemotherapeutic control techniques. The poorly managed herds had higher level of parasitism compared to those having fair or good management (Yazwinski and Gibbs, 1975). Proper managemental practices based on biology of the parasite is the most effective control technique. Strategic anthelminthic treatment increases the productivity of cattle (Bandyopadhyay et al., 2010).

The study forms the first of its kind in mapping the gastrointestinal parasitic infection among cattle of an entire district of Kerala. The result of the present study will help in devising control strategies against these parasitic diseases in future. 


\section{Acknowledgements}

The authors are thankful to the Kerala State Council for Science Technology and Environment for funding the student project (016/SRSSP/2009/CSTE) entitled "Coprological survey on endoparasites causing gastroenteritis in cattle of Wayanad district of Kerala".

\section{References}

ADSS (Animal Disease surveillance Scheme), 2007. Department of Animal Husbandry, Kerala.

Bandyopadhyay, S., Mandal, S., Datta, K.K., Devi. P., De, S., Bera, A.K. and Bhattacharya, D. 2010. Economic analysis of risk of gastrointestinal parasitic infection in cattle in North Eastern States of India. Trop. Anim. Health Prod., 42(7): 1481-1486.

Birthal, P.S. and Jha, A. 2005. Review on emerging trends in India's livestock economy: implications for development policy. Indian J. Anim Sci., 75(10): 1227-32.
Coop, R.L. and Holmes, P.H. 1996. Nutrition and parasite interaction. Int. J. Parasitol., 26(8-9): 951-962.

Coop, R.L. and Kyriazakis, I. 1999. Nutritionparasite interaction. Vet. Parasitol., 84(3-4): 187-204.

Quinquennial Livestock Census, 2007. Department of Animal Husbandry, Kerala, India.

Radostits, O.M., Gay, C.C., Blood, D.C. and Hinchkliff, H.W. 2000. Veterinary Medicine- A textbook of diseases of cattle, sheep, pigs, goats and horses. Ninth edition. W.B. Saunders Company Ltd., New York, 1339-1343.

Soulsby, E.J.L. 1981. Helminths, arthropods and protozoa of domesticated animals Bailliere and Tindall, London, 291-294.

Sutherland, I. and Scott, I. 2010. Gastrointestinal nematodes of sheep and cattle, Biology and control. WileyBlackwell, John Wiley and Sons Limited, UK, 33-34.

Yazwinski, K.A. and Gibbs, H.C. 1975. Survey of helminth infection in Maine dairy cattle. J. Vet. Res., 36(11): 1677 82.

\section{How to cite this article:}

Mathew Abraham, Pallippatt Thoomban Harshal, Karapparambu Gopalan Ajithkumar and Reghu Ravindran. 2017. Coprological Survey of Gastrointestinal Parasites of Dairy Cattle in Wayanad, Kerala, India. Int.J.Curr.Microbiol.App.Sci. 6(2): 899-903. doi: http://dx.doi.org/10.20546/ijcmas.2017.602.100 